\title{
Participatory Development Strategy: and Effect on Community in Punjab (A Case Study of Water Supply and Sanitation)
}

\author{
Prof. Dr Haq Nawaz Anwar
}

Chairperson, Department of Sociology

\author{
Aamir Hayat \\ Khan.aamirhayat@yahoo.com
}

Irfan Mehmood Janjua

Attique ur Rehman, 2,3,4, M.phil scholar, Department of Sociology, Government College University Faisalabad, Pakistan

Doi:10.5901/ajis.2014.v3n6p47

\section{Abstract}

\begin{abstract}
Community participation has become one of the significant features of new development paradigm. It has been spread all over the world through different methods that lead toward the sustainable development. The dynamic interaction between the achievement of specific objectives for improving the provision of resource position of the local community and the specific identity of community leads by the process of participatory development. Therefore, present research was giving an overview of the effects of participatory development on community in Punjab. It was also examine the involvement of community in the developmental projects and its effects on community. The study was confined to two cities of Punjab, Pakistan and 300 respondents were selected through Systematic random sampling and Proportionate Sampling Technique. There are many different methods of collecting data, depending on the objective and nature of the study, availability of resources etc. in the present study; the data were collected with the help of interviewing schedule. After field work the data were analyzed by using Statistical Package for Social Sciences (SPSS). In conclusion, the researchers were suggest some strategies to improve the participatory development.
\end{abstract}

Keywords: Community participation, Sustainable Development, Dynamic Interaction, Specific Objectives

\section{Introduction}

Active public participation is believed to be a significant component of interventions and it is considered directly proportional to the success of development projects. Distinctive studies and surveys have highlighted that community participation enhances the nature of result and it brings about valuable, productive and feasible advancement. The volubility of community participation being developed has further been illustrated as Participation is required to guarantee that ventures are better composed, profits better targeted, project inputs delivered in more cost effective and timely manner, and that extend profits are disseminated all the more impartially and with more modest spillages because of defilement and other lease looking for action.

From the last decades the funded developmental projects was failed due to top-down approaches to development. Due to failure of these projects the developing nations cannot provide the basic needs and the mostly projects suffer from the lack of sustainability and the basic reason is lack of community participation. The new slogan started in 1980 was the participatory development or community led development and the world was jumped toward the participatory development. Such community-based approaches to development are among the fastest growing mechanisms for channeling development assistance according to conservative calculations, the World Bank's lending for CDD (community-driven development)projects has gone up from \$325 million in 1996, to \$2 billion in 2003 (Mansuri and Rao, 2003).

Individuals' participation being developed utilized overall including Pakistan is an ideal approach to attain reasonable improvement. This study reasons that cooperation is an option to the bottom up methodology. Different methodologies to include individuals being developed activities and projects have been produced and embraced in 
different nations. So also, different techniques, level, degree and types of cooperation have developed demonstrating the quality and degree of interest. The general aftereffects of the study helps in building the degree to the degree individuals' participatory methodology remains in term of need, comes about and level of achievement in writing and practice ( Shah and Baporikar,2012).

Current patterns are really steady for group based improvement and a large portion of the contributor organizations want to reserve those trusts which include community participation. The obstructions that make issues for all the stakeholders to convey better administrations to group. There must be systems to enhance the relationship between all the stockholders. Intrusion of world class parts in group likewise hindering component and require a dire consideration as practically all the formative tasks enduring as a result of nearby tip top group parts. Group investment being developed is troublesome methodology. There is necessity of synchronization between the legislature and community participation. This study introduced a percentage of the blocking variables of group support. There is have to investigate interior components which additionally hinder the group cooperation. Group advancement could be improved by just bringing down feedback and gratefulness for fruitful stories of group embedded ventures which enhances the spirit of different groups (Ahmad, 2011).

In past, Pakistan has experienced many failures relating to the developmental projects in rural and urban areas regarding Water and Sanitation. These failures are often attributed to the approach used by the government in not involving the community in project development and management. Currently, there is a move to review these projects by involving the communities in project identification, implementation and monitoring activities. The purpose of this study is to examine effects of participatory development on the communities and their effect on long term sustainability of these projects. In addition, the study were examine strategies that were ensure the availability of physical and human resources to maintain the established facilities and expand coverage as widely as possible in a manner that is sustainable.

\section{Research Methodology}

Methodology is the logic of scientific procedure. Methodological technique and way of analyzing the observation are important to sociological pursuits and empirical research. It helps us to describe and explain research design and techniques of research the validity and precision of a study may give a misleading picture unless the study has not been put to rigorous and scientific methodology

Quantitative method were used by the researchers for the present study, two community participatory projects situated in Lahore and Lodhran were taken as a universe. These two districts were appropriate for the present study because these two projects (Changa Pani Project and Lodharan Pilot Project) were completed with participation of community. The sample of 300 respondents was selected through Systematic random sampling technique and Proportionate Sampling techniques. The interviews were conducted with the help of interview schedule. A main reason to use interview schedule instead of the questionnaire was that some of the respondents were illiterate. After the completion of data collection, it was coded and analyzed with help of SPSS (Statistical Package for the Social Sciences) and Chi Square-Test was applied to test the hypothesis.

\section{Results and Discussion}

In this study 300 head of household were selected from the two cities Lahore and Lodhran in counting 200 from Lahore and 100 from the Lodhran were taken for the collection of information.

\begin{tabular}{|l|l|}
\hline Characteristic Frequency Percent & Characteristic Frequency Percent \\
\hline Response 300100 & Response 300100 \\
$\frac{\text { Area }}{\text { Lahore } 20066.66}$ & Education \\
Lodhran 10033.34 & Iliterate 299.7 \\
$\frac{\text { Age }}{21-30} 4715.7$ & Literate 6521.7 \\
$31-408428$ & Primary 8528.3 \\
$41-509130.3$ & Middle 5217.3 \\
$51-606722.3$ & Matriculation 22 7.3 \\
61 and above 113.7 & Intermediate 3712.3 \\
\hline
\end{tabular}




\section{Age Composition}

The respondent's age is classified in to five categories. This table 1 shows that $15.7 \%$ respondent were in the age group of 21-30 years, $28 \%$ respondent were in age of 31-40 years, again 30.3\% respondent were in the age group of $41-50$ years, $22.3 \%$ respondents were in age of $51-60$ years and remaining 3.6\% respondents were in the age of 61 years and above.

\section{Educational Status of Respondents}

Table 1 reveals that (28.3\%) respondents were primary pass, 21.7\% respondents were literate, just $7.3 \%$ respondents were pass the matriculation level, while $9.7 \%$ respondents were illiterate $12.3 \%$ respondents were intermediate $8 \%$ of the respondents were graduation and only $0.7 \%$ respondents have master and above education.

Table 2: Common Water Born Disease before and after Project Implementation

\begin{tabular}{|l|c|c|c|c|}
\hline \multirow{2}{*}{ Common Disease } & \multicolumn{2}{|c|}{ Before Project } & \multicolumn{2}{c|}{ After Project } \\
\cline { 2 - 5 } & $\mathrm{F}$ & $\%$ & $\mathrm{~F}$ & $\%$ \\
\hline Gastro & 83 & 27.7 & 41 & 13.7 \\
\hline Diarrheal & 62 & 20.7 & 35 & 11.7 \\
\hline Hepatitis & 125 & 41.7 & 68 & 22.7 \\
\hline No disease & 0 & 00 & 121 & 40.3 \\
\hline Don,t know & 30 & 10.0 & 35 & 11.7 \\
\hline Total & 300 & 100.0 & 300 & 100.0 \\
\hline
\end{tabular}

\subsection{Common Water Born Disease before and after Project Implementation}

Table 2 examine that $27.7 \%$ respondents said that Gastro was common disease in the area before implementation of project,20.7\% respondents answered that Diarrheal was common disease before the project, $(41.7 \%)$ respondents replied that Hepatitis were common disease and $10.0 \%$ respondents don't know about common disease in the area before water supply and sanitation project.

\subsection{Common Water Born Disease after Project Implementation}

Results shows that $13.7 \%$ respondents said that Gastro is common disease in the area at present, $11.7 \%$ respondents answered that Diarrheal is common disease, $22.7 \%$ respondents replied Hepatitis is common disease and majority of the respondents (40.3\%) said that there is no disease in area related to drinking water and sanitation while remaining $11.7 \%$ respondents said that they don't know about common disease in the area water supply and sanitation project.

\section{Type of Community Contribution}

\begin{tabular}{|c|c|c|}
\hline Type of Community Contribution & Frequency & Percent \\
\hline In kind form & 72 & 24.0 \\
\hline Cash & 183 & 61.0 \\
\hline Both & 45 & 15.0 \\
\hline Total & 300 & 100.0 \\
\hline
\end{tabular}

Table 3 shows that majority of respondents (61.0\%) respondents were contribute in the project in the shape of cash, $24.0 \%$ respondents were contribute in the kind form while $15.0 \%$ respondents were contribute in both shapes cash and in kind form for the water supply and sanitation project. 


\section{Feeling of Community about Ownership}

\begin{tabular}{|c|c|c|}
\hline Ownership of Material & Frequency & Percent \\
\hline Own property & 155 & 51.7 \\
\hline Govt property & 109 & 36.3 \\
\hline No Opinion & 36 & 12.0 \\
\hline Total & $\mathbf{3 0 0}$ & $\mathbf{1 0 0 . 0}$ \\
\hline
\end{tabular}

Table 4 depicts that (51.7\%) of the respondents replied that material of water supply and sanitation is their own property $36.3 \%$ respondents said that this is Government property and remaining $12.0 \%$ respondents did not give any response about the ownership water supply and sanitation material.

\section{Testing of Hypothesis}

Hypothesis is a formal statement that presents the expected relationship between an independent and dependent variable (Creswell, 1994).

Association between the Level of Participation and ownership of community about project material Hypothesis: Higher the level of participation (contribution in cash and kind) of community:

Higher will be ownership of community about project material

\begin{tabular}{ccccc}
\hline \multirow{2}{*}{ Feeling about ownership of Material } & \multicolumn{3}{c}{ Community Participation } & \multirow{2}{*}{ Total } \\
\cline { 2 - 4 } & In kind & Cash & Both & \\
\hline Own Property & $26(8.7 \%)$ & $101(33.7 \%)$ & $28(9.3 \%)$ & $155(51.7 \%)$ \\
Govt Property & $27(9.0 \%)$ & $69(23.0 \%)$ & $134.3 \%$ & $109(36.3 \%)$ \\
No opinion & $19(6.3 \%)$ & $13(4.3 \%)$ & $4(1.3 \%)$ & $36(12.0 \%)$ \\
\hline Total & $72(24.0 \%)$ & $183(61.0 \%)$ & $45(15.0 \%)$ & $300(100.0 \%)$ \\
\hline Chi-square $\chi^{2}=22.032$, d.f. $=4$ & , P value $=.000^{*}$ Gamma $=-.329^{*}=$ Highly significant \\
\hline
\end{tabular}

The calculated value of Chi-square $\chi^{2}(22.03)$, degree of freedom is 4 and P-value $=(.000)$. So it shows that the calculated value is less than tabulated value at significance level 0.05 . P-value .000 is less than at significance level of 0.05 (i.e. $.000<$ P) so the hypothesis is accepted. Gamma value shows a strong negative relationship between the variables. So the hypothesis "Higher the level of participation (contribution in cash and kind) of community: Higher will be ownership of community about project material" is accepted.

\section{Discussion}

Urbanization is also a cause of concern. Over a third of Pakistan's population live in urban areas; and it is estimated that by 2015 , if this trend continues, 52.8 million people will be deprived of safe drinking water and 43.2 million people will have no access to adequate sanitation facilities. These facts coupled with inadequate sanitation and limited knowledge of hygienic practices, contributes to the deaths of thousands of people each year from diarrheal diseases (Water Aid, 2010).

In the present study results shows that the common disease like Hepatitis (41.7\%) Diarrheal Gastro etc before the projects but after the implementation of participatory development projects (40.3\%) said that there is no disease in area related to drinking water and sanitation. It shows the projects with participation of community (related water and sanitation) have much effect on community health.

\section{Conclusion}

The major objectives of this study were to check the effects of Participatory Development on Community in Punjab (A study on Water Supply and Sanitation in Punjab).On the basis of above discussion, it is concluded that participatory approach has partially succeeded in mobilizing and strengthening the community organizations in the project area. Participatory development gives the community feeling of ownership and community care the water supply and sanitation material as their own property. Results shows that this approach have change the community living standard, social life, decrease the expenses on health, water and sanitation and the community were satisfied with expenses and quality of drinking water. 


\section{References}

Ahmad .S.,Noraini .D.M. Talib.(2011).A; External Factors that inhibit community participation in development International Journal of Economics and Resource. 2(1), 16-22.

Ahmad. M.,Z, 2005"Pakistan - Water and Sanitation Services in a Devolved Government System," 31st WEDC International Conference (Kampala) (2005), accessed December 10, 2014.

Battacharyya, A., T. R. Harris, R. Narayanan and K. Raffiee. "Technical Efficiency of Rural Water Utilities." J. Agr. \& Res. Econ. 20(1995): 373-391.

Bonfiglioli, A. (1997). Participation and grass-roots organizations in integrated range and livestock development, Pakistan-Part 2. FAO/UNDP integrated range and livestock development project, Balochistan, Pakistan.

Cohen, J.M. and Uphoff, N.T. (1977). Rural development participation: concepts and measures for project design, implementation and evaluation. Cornell university, center for international studies. Ithaca, New York.

CPA (2009) Participation provides equitable development and creates a sense of self-determination, community development and selfdevelopment

Deshler, D. and Sock, D. (1985). Community development participation: a concept review of the international literature. Paper presented in conference "international league for social commitment in adult education". Linungskile, Sweden, July, 22-26.

Mansuri.G.,Rao.V. (2003). "Evaluating Community-Based and Community-Driven

Shah.A.,I. Baporikar.N.(2012).Participatory Approach to Development in Pakistan Journal of Economic and Social Studies.6(2), 5-18.

Water Aid (2010"Country Information: Pakistan,"), accessed February 25, 2014, 
